\title{
USO E A DIFUSÃO DA LINGUA BRASILEIRA DE SINAIS NA ESCOLA COMUM
}

\author{
THE USE AND DIFFUSION OF BRAZILIAN SIGN LANGUAGE \\ IN COMMOM SCHOOL
}

EL USO Y LA DIFUSIÓN DE LENGUA DE SEÑAS EN LA ESCUELA NORMAL

Pamela Estefani Corá*

https://orcid.org/oooo-0002-1772-6815

Anderson de Abreu**

https://orcid.org/oooo-0oo1-8925-6878

Patrícia Graff***

https://orcid.org/oooo-0002-3315-2401

REVISTA PEDAGÓGICA

Revista do Programa de Pós-graduação em Educação da Unochapecó | ISSN 1984-1566

Universidade Comunitária da Região de Chapecó | Chapecó-SC, Brasil

Como referenciar este artigo: CORÁ, P. E.; ABREU, A.; GRAFF, P. Uso e a difusão da língua brasileira de sinais na escola comum. Revista Pedagógica, Chapecó, v. 22, p. 1-18, 2020. DOI: http://dx.doi.org/10.22196/rp.v22io.4570

Resumo: O uso e a difusão da Libras, por estudantes ouvintes que têm acesso a esta língua no decorrer do processo de escolarização, constituem o tema desta pesquisa, cujo objetivo foi identificar se, no cotidiano escolar, os alunos difundem e fazem uso desta língua como meio de comunicação com os surdos. Trata-se de uma pesquisa de campo de natureza qualitativa e de cunho etnográfico, observando o comportamento de um grupo de indivíduos no cotidiano escolar. A pesquisa mostra que os alunos ouvintes fizeram uso da língua de sinais dentro da escola, com algumas especificidades como: a) diferença de uso da língua entre os gêneros masculino e feminino; b) maior aproximação com a língua de sinais no grupo de escolares que frequentam os Anos Iniciais do Ensino Fundamental; c) importância do professor bilíngue dentro da escola, no diálogo com todos os alunos. Conclui-se que a língua de sinais é importante para os alunos ouvintes e surdos dentro da escola comum, possibilitando a inclusão do aluno surdo.

Palavras-chave: Libras. Ouvinte. Apoio pedagógico. Políticas educacionais.

Abstract: The use and the promotion of the Brazilian Sign Language (LIBRAS) by typically-hearing students that have access to this language during the schooling process compose the theme of this research, that aims to identify if, in the school routine, the students promote and make usage of this language as a means of communication with deaf people. It is a qualitative field research with ethnographic characteristics, observing the behavior of a specific group of people in school routine. The research shows that typically-hearing students did make use of the sign language inside the school, with some specificities like: a) different use of the language between male and female genders; b) bigger approach to the sign language by students from the first years of Elementary School; c) the value of the bilingual teacher inside school and his/her way of interacting with all the students. It is possible to conclude that sign language is important to all typically-hearing and deaf students inside regular school, making it possible for the deaf student to be included.

Keywords: Brazilian Sign Language. Typically-hearing students. Pedagogical support. Educational policies.

Resumen: El uso y la difusión de la lengua brasileira de señas (Libras) para estudiantes oyentes que tienen acceso a esta lengua en el proceso de escolarización es el tema de investigación de esta tesis de pregrado. Nuestro objetivo fue identificar si, diariamente, los alumnos promueven y utilizan esta lengua como medio de comunicación con los alumnos sordos. Esta investigación es el resultado de un trabajo de campo de análisis cualitativo y etnográfico, en el cual se observaron el comportamiento de un determinado grupo de alumnos en el cotidiano escolar. La investigación demuestra que los estudiantes utilizan la Libras dentro de la escuela con algunas especificaciones, tal como: a) hay una diferenciación en la utilización de la lengua de señas entre los géneros masculino y femenino; b) Los alumnos de los años iniciales de primaria son los que más utilizan de la lengua de señas; c) la relevancia de un profesor bilingüe dentro de la escuela que pueda dialogar con todos los estudiantes. Concluimos que la enseñanza de Libras es importante para los estudiantes oyentes y sordos dentro de la escuela, pues permite la inclusión de los alumnos sordos.

Palabras clave: Lengua de señas. Oyente. Apoyo pedagógico. Políticas educativas. 


\section{Introdução}

A Língua Brasileira de Sinais (LIBRAS) constitui uma língua reconhecida no Brasil desde o ano de 2002 - quando foi aprovada a Lei $\mathrm{n}^{0} 10.436 / 2002$, que em seu Art. $1^{\circ}$ a reconhece "como meio legal de comunicação e expressão" (BRASIL, 2002, s/p). Essa lei pode ser considerada recente quando olhamos para o contexto de mudanças nos campos linguísticos e culturais. Há apenas 18 anos a LIBRAS foi reconhecida linguisticamente no Brasil e, talvez por isso, as experiências de ensino dessa língua, na Educação Básica, ainda são bastante esparsas. No Ensino Superior, a inserção obrigatória de um componente curricular para o ensino de LIBRAS - via Decreto 5.626/2005 -, tem possibilitado que os professores em formação produzam conhecimentos básicos sobre essa língua, que servirão como base para a atuação docente junto aos alunos surdos.

Nesta pesquisa problematizamos o uso e a difusão da LIBRAS entre ouvintes e as suas contribuições ao ensino comum ${ }^{1}$. A pesquisa foi realizada em uma escola da rede estadual de educação, no município de Chapecó/SC, por meio de observações do cotidiano escolar, focadas em estudantes ouvintes e surdos que frequentam o ensino comum e têm, ao longo do processo de escolarização, o acesso à LIBRAS. Conforme registros da secretaria da escola, no ano de 2019 havia nove alunos surdos matriculados na Educação Básica.

A escola, lócus da pesquisa, é a mais antiga do município, tendo iniciado seus trabalhos em meados de 1930. Ao longo de sua história passou por diversos processos de nomeação e em 1971 passou a denominação atual: Escola de Educação Básica Marechal Bormann. Segundo o seu Projeto Político Pedagógico - PPP - (2018), em 1981 foi criada a Sala de Recursos para Deficientes Auditivos, hoje denominada Sala de Recursos para Portadores ${ }^{2}$ de Necessidades Especiais, que atende toda a região, sendo reconhecida como Escola Pólo para a escolarização de surdos. Cumpre assinalar que essa escola atende todas as etapas da Educação Básica, desde a Educação Infantil até o Ensino Médio.

O histórico da escola se tornou um critério fundamental para que a definíssemos como lócus da pesquisa. Trata-se de uma das escolas pioneiras na inclusão de alunos surdos, no contexto da educação comum em Chapecó, tendo experiência acumulada no ensino de LIBRAS para alunos ouvintes e surdos. A partir desse contexto buscamos identificar os usos que alunos ouvintes e surdos fazem da LIBRAS nos espaços da escola, tendo como problema de pesquisa: como o estudante ouvinte, que têm acesso a Língua Brasileira de Sinais no decorrer do processo de
* Graduada em Pedagogia - Universidade Federal da Fronteira Sul.

E-mail: pamela_cora@hotmail.com

** Graduado em Pedagogia - Universidade Federal da Fronteira Sul.

E-mail: anderdeabreu23@gmail.com

*** Doutora em Educação (UNISINOS), Docente na Universidade Federal da Fronteira Sul.

E-mail: patricia.graff@uffs.edu.br

1 Usaremos o termo escolas/ensino comum por entendermos que existem escolas especiais e que seu funcionamento e organização também é regular, portanto, cabe melhor o termo comum para referir a escola convencional.

2 O termo "Portadores" utilizado no PPP da escola, não é mais utilizado. A terminologia atual refere a pessoa com deficiência. 
escolarização, difunde e faz uso desta língua no cotidiano escolar? Ao responder a essa pergunta pudemos distinguir se os estudantes têm domínio sobre a LIBRAS e compreender a importância do ensino dessa língua desde o início do processo de escolarização.

Importa marcar que a presença de surdos em nossa sociedade está cada vez mais visível. Conforme os dados do último censo demográfico (2010), divulgado pelo Instituto Brasileiro de Geografia e Estatística (IBGE), no Brasil existem cerca de 9.717 .318 pessoas que declaram ter algum tipo de deficiência auditiva (BRASIL, 2012). No município de Chapecó/SC esse número soma um total de 8.656 pessoas, distribuído entre os indivíduos com perda total ou parcial de audição. A pesquisa do IBGE não levanta dados sobre o uso da LIBRAS, o que faz com que o número de usuários se dilua no número total de deficientes auditivos e não nos permite informá-lo com precisão. No entanto, é provável que uma parcela desse contingente utilize a Língua Brasileira de Sinais para a comunicação, o que justifica a sua difusão entre surdos e ouvintes.

Se incluir é garantir o acesso de todos aos bens culturais, materiais e imateriais, construídos pela humanidade no seu processo de socialização, então temos que pensar que uma língua - que é um bem imaterial e cultural - precisa ser usada pelos diferentes indivíduos, a fim de possibilitar o acesso aos meios criados para a sobrevivência em sociedade. Nessa cena, o ensino de LIBRAS para ouvintes parece-nos constituir uma importante contribuição para promover a inclusão de surdos. As escolas, ao abrirem espaço para o ensino de línguas de sinais, abrem portas para que haja o fortalecimento da inclusão.

Com intuito de orientar o leitor, destacamos que a organização deste artigo traz, em sua introdução, o tema e o problema de pesquisa, assim como a motivação para desenvolvê-la. Na sequência apresentamos os procedimentos metodológicos usados para a realização da pesquisa e os resultados e discussões, organizados a partir da produção de três ênfases principais, que tomam como princípio a recorrência de acontecimentos ao longo das observações em campo, a saber: 1) a importância do professor bilíngue dentro da escola, no diálogo com todos os alunos; 2) a diferença de uso da língua entre os gêneros masculino e feminino, e; 3) a maior aproximação com a língua de sinais no grupo de escolares que frequentam os Anos Iniciais do Ensino Fundamental. Nelas mostramos o caminho percorrido para a realização da pesquisa e as análises produzidas sobre os elementos descritos no diário de campo, que constituem os dados coletados e analisados, a partir das aproximações possíveis. Por último, trazemos as considerações finais da pesquisa. 


\section{Procedimentos metodológicos}

A presente pesquisa percorreu um caminho qualitativo, de cunho etnográfico por dedicar-se a observar, minuciosamente, o comportamento de um grupo de estudantes ouvintes e surdos, em sua comunicação por meio da Língua Brasileira de Sinais. A abordagem etnográfica na investigação científica, segundo Mattos e Castro (2011, p. 10), destina-se a "obter uma descrição densa, a mais completa possível sobre um grupo particular de pessoas e o significado das perspectivas imediatas que eles têm do que fazem".

Para tentar compreender o campo pesquisado, realizamos um levantamento de pesquisas sobre o tema, na plataforma de periódicos da Coordenação de Aperfeiçoamento de Pessoal de Nível Superior (CAPES). Utilizamos os pares de descritores: "LIBRAS/ouvinte", que resultou em 76 trabalhos, dentre os quais selecionamos 2; "Ensino de LIBRAS/ouvinte", com 61 artigos, dentre os quais selecionamos 2; "ensino de LIBRAS/inclusão", com 141 resultados, dentre os quais selecionamos 4. Os resultados foram analisados a partir da leitura dos títulos, das palavras-chave e dos resumos. Por meio dessa seleção, encontramos 08 artigos que se aproximavam do objetivo da pesquisa, os demais foram descartados, por não se mostrarem compatíveis com o foco da pesquisa, qual seja: o uso e a difusão da LIBRAS por pessoas ouvintes; por se repetirem entre os resultados; por referir aos processos de escolarização de surdos e/ou por tomar o ensino da LIBRAS para ouvintes no Ensino Superior, como foco investigativo.

Os artigos selecionados foram: Análise das condições organizadas em uma escola para promover a inclusão de alunos surdos, escrito por Katia Tavares Merselian, Celia Regina Vitaliano; A questão linguística na inclusão escolar de alunos surdos: ambiente regular inclusivo versus ambiente exclusivamente ouvinte; de autoria de Patricia Aspilicueta, Carla Delani Leite, Emileine Cristine Mathias Rosa e Gilmar de Carvalho Cruz; Alunos com surdez e o processo de inclusão: uma análise de discursos sobre língua de sinais, escrito por Daniella Cristina Bosco, Sandra Eli Sartoretto de Oliveira Martins e Cláudia Regina Mosca Giroto; Ensino de Libras: uma atividade do Pibid para estudantes do ensino infantil de uma escola municipal da cidade de Campo Grande, escrito por Cristiane Ribeiro Albres, Rosana de Fátima Janes Constâncio e Alessandra Souza da Cruz Daniel; Política para uma educação bilíngue e inclusiva a alunos surdos no município de São Paulo, produzido por Cristina Broglia Feitosa de Lacerda; Neiva de Aquino Albres e Silvana Lucena dos Santos Drago; A inclusão escolar de alunos surdos: o que dizem alunos, professores e intérpretes sobre esta experiência, escrito por Cristina 
Broglia Feitosa de Lacerda; O ensino da Língua Brasileira de Sinais na educação infantil para crianças ouvintes e surdas: considerações com base na psicologia histórico - cultural, produzido por, Hivi de Castro Ruiz Marques, Sonia Mari Shima Barroco e Tânia dos Santos Alvarez da Silva, e; O que dizem/sentem alunos participantes de uma experiência de inclusão escolar com aluno surdo, escrito por Cristina Broglia Feitosa de Lacerda. A leitura dos artigos, na íntegra, instrumentalizou as discussões sobre os dados da pesquisa - registrados em diário de campo -, na parte analítica deste artigo.

Ainda no segundo semestre de 2018, o projeto de pesquisa foi encaminhado à Gerência Regional de Educação (GERED), para a autorização da pesquisa de campo e, posteriormente, submetido ao Comitê de Ética em Pesquisa (CEP/UFFS), com parecer de aprovação $\mathrm{n}^{0}$ 3.199.862. Com a autorização do CEP/UFFS, começamos a fazer as observações no espaço escolar. Por meio delas foram produzidos os dados da pesquisa, que foram registrados em diário de campo e, posteriormente, analisados. As observações ocorreram durante os momentos de intervalo, quando os alunos - surdos e ouvintes - circulavam livremente pelo pátio da escola, a partir de uma distância que assegurasse a não interferência dos pesquisadores nas situações observadas. As idas a campo foram realizadas em um espaço de tempo de três semanas, totalizando dez turnos de observação, divididos entre os períodos da manhã e da tarde.

Os participantes, embora não tenham sido abordados e nominados, compuseram a pesquisa a partir da comunicação que estabeleceram em LIBRAS. Por meio dela foi possível o reconhecimento dos alunos surdos e ouvintes que faziam uso dessa língua. A estratégia metodológica utilizada foi, primeiramente, identificar os alunos surdos no espaço escolar, para, posteriormente, perceber se os alunos ouvintes faziam uso ou não desta língua para se comunicar com eles. Buscamos, também, identificar os lugares que eles mais frequentavam na escola e assim observar um número mais significativo de situações que envolvessem a comunicação em LIBRAS. Todas as situações observadas foram registradas em diário de campo e, posteriormente, analisadas. Para a análise dos dados coletados, tentamos identificar a recorrência dos acontecimentos durante as observações. Por meio da repetição desses acontecimentos produzimos três ênfases principais, que foram aparecendo com mais frequência ao longo da pesquisa e serão apresentadas e discutidas na sequência.

\section{Resultados e discussões}

A Língua Brasileira de Sinais teve a sua origem na Língua de Sinais Francesa, em meados do século XIX. 
No entanto, somente com a aprovação da Lei $\mathrm{n}^{0} 10.436$, de 24 de abril de 2002, foi reconhecida linguisticamente, passando a assumir um status de língua brasileira. Nesse registro, sinalizamos que a LIBRAS constitui a língua materna dos surdos brasileiros, assumida como a sua primeira língua (L1), sendo, prioritariamente, ensinada antes da Língua Portuguesa escrita, que figura como a segunda língua (L2).

Em uma perspectiva bilíngue, o ensino das duas línguas viabiliza a aprendizagem para os alunos surdos, pois torna o conhecimento acessível tanto na sua língua materna como na língua utilizada no país onde nasceram. Para Marques, Barroco e Silva (2013, p. 511), "o bilinguismo refere-se ao domínio e uso de duas línguas. No Brasil, o bilinguismo para os surdos estabelece o uso da LIBRAS, como primeira língua e da língua portuguesa na modalidade escrita, como segunda língua”. Sobre o bilinguismo, Kelman, Lage e Almeida (2015, p. 126-127) ainda destacam que caracteriza "a capacidade de se utilizarem duas línguas em momentos e contextos diferentes. A maioria das crianças tem a capacidade e a facilidade de aprender mais de uma língua. [Constituem] vantagens de ser bilíngue[:] aprender novas palavras facilmente e comunicar-se com um número maior de pessoas".

Conforme o Decreto ${ }^{0} 5.626 / 2005$, a LIBRAS deve ser inserida como componente curricular obrigatório nos currículos dos cursos de graduação, como as Licenciaturas e a Fonoaudiologia (BRASIL, 2005). Além da obrigatoriedade do ensino de LIBRAS nas licenciaturas - possibilitando que os professores em formação tenham acesso a essa língua e conheçam as especificidades relacionadas à surdez -, o referido Decreto regulamenta os processos formativos de professores, instrutores de LIBRAS e tradutores/intérpretes, bem como prevê as garantias necessárias para viabilizar o direito dos surdos à educação e à saúde. No entanto, a obrigatoriedade do ensino de LIBRAS não se refere à Educação Básica, o que dificulta a sua inserção nos currículos do ensino comum. Visando à inclusão curricular da LIBRAS na Educação Básica, está em tramitação, no Congresso Federal, o projeto de Lei $\mathrm{n}^{0}$ 2.040/11 (COMISSÃO, 2019), que visa possibilitar o ensino dessa língua para os escolares ouvintes e surdos, em municípios com mais de 10 mil habitantes. No entanto, este projeto de Lei teve parecer desfavorável na Comissão de Constituição, Justiça e Cidadania (CCJC), emitido na reunião do dia 15 de maio de 2019.

Na contramão do que indica a legislação atual, na escola pesquisada a LIBRAS não faz parte do currículo escolar como disciplina, mas o seu ensino - ministrado por professores bilíngues - ocorre semanalmente nas turmas 
em que há escolares surdos matriculados, por meio da cedência de períodos, por parte dos professores que ministram as disciplinas que compõem o currículo escolar. No entanto, não conseguimos acompanhar nenhuma aula da LIBRAS pois, quando realizamos as observações, essas aulas ainda não haviam iniciado nas turmas. Mesmo reconhecendo o esforço da escola em promover o ensino da LIBRAS, a dependência da boa vontade dos professores em ceder parte das suas aulas a esta atividade parece expressar o lugar secundário que a LIBRAS ocupa na escola. Ou seja, além de não fazer parte do currículo escolar, para ser efetivada depende de doações de carga horária dos professores. Também chama a atenção o fato de, em março de 2019, o ano letivo já ter começado, mas as aulas de LIBRAS ainda não.

Ainda sobre o campo em investigação, cumpre assinalar que se filia a uma perspectiva educacional inclusiva, impulsionada, no Brasil, pela Política Nacional de Educação Especial na perspectiva da Educação Inclusiva (BRASIL, 2008). Nessa matriz, começa a operar, no contexto escolar, um conjunto de profissionais de apoio (FRÖLICH, 2018). Dentre eles destacamos a presença de tradutores/ intérpretes de Língua Brasileira de Sinais/Língua Portuguesa - cuja função consiste em fazer a tradução/interpretação de mensagens entre a LIBRAS e a Língua Portuguesa, intermediando a comunicação -; de professores bilíngues - que adaptam o conteúdo das mensagens para os alunos surdos e facilitam a comunicação -, e; de professores de Atendimento Educacional Especializado - que trabalham em conjunto com os professores de ensino comum, professores bilíngues e tradutores/intérpretes na promoção das condições de acessibilidade, que facilitem a aprendizagem dos alunos surdos.

Nesse contexto educacional, importou, para as nossas observações, a circulação da Língua Brasileira de Sinais, nos momentos de interação livre, entre surdos e ouvintes, para que pudéssemos dimensionar o uso e a difusão dessa língua no contexto pesquisado, considerando o ensino sistemático e contínuo dessa língua na escola pesquisada, nas turmas em que os alunos surdos estão matriculadas. No entanto, não descartamos as mediações empreendidas pelos profissionais de apoio, para caracterizar o contexto pesquisado.

Nesse contexto, a partir das orientações produzidas no âmbito da rede estadual de educação de Santa Catarina - mantenedora da escola pesquisada -, trazemos algumas definições mais precisas para a atuação dos profissionais de apoio. $\mathrm{O}$ documento normativo da rede estadual pontua que ao tradutor/intérprete de LIBRAS/Língua Portuguesa (nominado neste estado como intérprete de LIBRAS) cabe 
o exercício de tradução e de interpretação das trocas comunicativas estabelecidas entre surdos e ouvintes no ambiente escolar, contribuindo para a difusão dessa língua e para a inclusão de surdos no ensino comum. Cumpre assinalar que as orientações produzidas pela Secretaria de Estado da Educação de Santa Catarina (SANTA CATARINA, 2018) omitem a tradução de textos que possam se apresentar em qualquer uma das línguas - LIBRAS e Língua Portuguesa -, do conjunto de atribuições relacionadas a esse profissional.

Ao professor bilíngue cabe oferecer "suporte e acompanhamento na aprendizagem de estudantes com surdez, usuários da Língua Brasileira de Sinais (Libras), que não tenham fluência na Libras" (SANTA CATARINA, 2018, p. 41). Os trabalhos do professor bilíngue e do tradutor/ intérprete são bastante semelhantes, embora o exercício profissional do professor bilíngue se estabeleça, predominantemente, nos Anos Iniciais do Ensino Fundamental, ao passo que o tradutor/intérprete atua nos Anos Finais do Ensino Fundamental e no Ensino Médio. Essa diferenciação se justifica pelo nível de fluência dos escolares na LIBRAS, pois muitos deles iniciam o processo de escolarização desconhecendo-a ou com pouca fluência nessa língua.

Lacerda, Albres e Drago (2013, p. 71), trazem uma atribuição que não foi prevista pela Secretaria de Estado da Educação de Santa Catarina, para o exercício deste profissional, caracterizando-o como o "professor com fluência em Libras que desenvolverá o ensino do português escrito com base em metodologias de ensino de segunda língua”. Importa marcar que o ensino da Língua Portuguesa, na modalidade escrita, para surdos constitui uma tarefa que exige empenho da escola e para a qual é necessário um conjunto de saberes e técnicas adequadas a condição linguística dos escolares surdos. Parece-nos que não a prever como atividade relativa ao professor bilíngue - profissional cuja formação é compatível com o ensino da Língua Portuguesa, na modalidade escrita, para surdos - pode dificultar a aprendizagem dessa língua, para esse grupo de escolares.

$\mathrm{Na}$ escola pesquisada, a tarefa de intermediar as trocas comunicativas entre surdos e ouvintes está atrelada à atuação da professora bilíngue. No entanto, em muitas situações, a sua atuação se caracteriza pelo ensino da LIBRAS para surdos e ouvintes, dadas as condições de fluência linguística na LIBRAS entre os escolares que frequentam os Anos Iniciais do Ensino Fundamental. Percebemos, durante as observações, que essas professoras assumem um papel importante na constituição de um repertório linguístico na LIBRAS para as crianças surdas e ouvintes, embora tenhamos notado o uso simultâneo da LIBRAS e da Língua Portuguesa, na modalidade oral, para mediar as 
comunicações entre os escolares. Essa dupla comunicação acontecia nos intervalos entre as aulas.

Entendemos que a utilização das duas línguas ao mesmo tempo produz o risco de sobreposição de uma língua em relação a outra e, no caso da LIBRAS, podem acontecer variações dessa língua, caracterizando-a como Português sinalizado, que se diferencia da LIBRAS em sua estrutura gramatical. Além disso, pode haver um prejuízo da língua materna dos surdos, que acabam aprendendo a estrutura linguística da língua majoritária, ou seja, a Língua Portuguesa.

Ao longo da pesquisa, percebemos a permanência de uma professora bilíngue junto aos alunos surdos e ouvintes no horário do intervalo. Nesses momentos, muitos alunos ouvintes repetiam os sinais em LIBRAS nos diálogos que estabeleciam e, também, durante as brincadeiras. Essa interação pareceu-nos fundamental para desenvolver o processo de inclusão dos alunos surdos, pela intermediação da professora. Conforme Ferreira e Zampieri (2009, p. 99),

A utilização de uma mesma linguagem entre sujeitos é essencial, pois é por meio dela que o sujeito se apropria dos conhecimentos que são conduzidos ao plano intrapessoal (operação interna), para, assim, orientar e controlar seu próprio comportamento. Ao internalizar os conhecimentos que foram significativos pelo outro, produz em si uma reconstrução interna de uma operação externa (interpessoal) propiciada pela linguagem.

Ao longo das observações, no refeitório, presenciamos diálogos entre professores bilíngues e alunos surdos e ouvintes. Em alguns momentos a instrutora de LIBRAS, que atua no Atendimento Educacional Especializado e no ensino de LIBRAS para a comunidade escolar, entrava na conversa e percebemos que, mesmo quando a comunicação se dava na Língua Portuguesa, as professoras bilíngues também oralizavam e sinalizavam ao mesmo tempo. Para ilustrar essas situações, trazemos um acontecimento pinçado do nosso diário de campo, quando a professora que realizava o trabalho no Atendimento Educacional Especializado (AEE) passava pelo refeitório, na hora do intervalo, e conversava com os alunos surdos oralizando e sinalizando ao mesmo tempo, da mesma forma que as professoras bilíngues faziam (Diário de campo do dia 03 de abril de 2019).

Nesse sentido, destacamos que o uso simultâneo das duas línguas é recorrente entre as professoras, tanto por aquelas que trabalham na sala de aula, como as que atuam na sala de recursos multifuncional. Arriscamos atribuir a essa prática à escassez de profissionais que pudessem 
atuar na escola para atender as necessidades dos alunos surdos e, também, dar conta de ensinar a LIBRAS aos alunos ouvintes. Ainda, parece-nos necessária uma atenção ao processo de formação continuada desses professores (bilíngues), para que percebam que o uso simultâneo das duas línguas não atende, satisfatoriamente, a nenhuma delas e, provavelmente, produz uma sobreposição da Língua Portuguesa em relação à LIBRAS, no que refere aos processos de aprendizagem e de compreensão do contexto em que os escolares estão envolvidos. Contudo, chama-nos a atenção a intensa demanda de alunos surdos e ouvintes durante os intervalos, o que mostra o uso contínuo da LIBRAS nos Anos Iniciais do Ensino Fundamental.

Acompanhamos, também, fragmentos da atuação de outro profissional, o tradutor/intérprete de LIBRAS/Língua Portuguesa. Ao longo das observações, chamou-nos a atenção o movimento de saída da sala de aula, produzido pelo tradutor/intérprete, juntamente com alguns alunos surdos. Percebemos que esse profissional, em alguns momentos, retirava os alunos surdos da sala de aula para fazer alguma explicação ou para realizar outra atividade com eles. Compreendemos que, quando o aluno não está na sala de aula, deixa de participar dos processos de ensino que nela são desencadeados e acaba sendo prejudicado no acompanhamento dos conteúdos e nas atividades desenvolvidas pela turma. Entendemos que o tradutor/intérprete não pode assumir a função de ensino, pois esta é a tarefa do professor. Tirando os alunos surdos da sala de aula, o tradutor/intérprete impede que a interação entre os alunos surdos, o professor e os colegas ouvintes aconteça. Mesmo reconhecendo a função indispensável que o tradutor/ intérprete de LIBRAS/Língua Portuguesa desempenha na escola, promovendo a interação comunicativa entre surdos e ouvintes, faz-se necessário assinalar o direito dos alunos surdos, de participarem de todas as atividades desenvolvidas na turma em que se encontram matriculados.

A partir da análise das interações e das atividades desenvolvidas pelos profissionais de apoio à escolarização dos alunos surdos, parece-nos possível inferir que a sua participação nos processos de escolarização é imprescindível para a materialização do ensino e da aprendizagem da LIBRAS para os alunos surdos e ouvintes, e da comunicação entre os escolares. Importa marcar, também, que esses profissionais cumprem um importante papel na difusão da LIBRAS e das especificidades linguísticas dos surdos, na comunidade escolar, com efeitos que se produzem sobre a sociedade, num sentido que ultrapassa os limites da escola, por meio de cada aluno que leva para as suas famílias as descobertas resultantes desse processo de aprendizagem e convívio. 
Um segundo ponto a ser destacado, a partir dos dados empíricos coletados na pesquisa de campo, sinaliza para uma diferença substantiva no uso da LIBRAS, entre os gêneros masculino e feminino. Percebemos que a maioria dos meninos que frequentam os Anos Finais do Ensino Fundamental e o Ensino Médio não utiliza a LIBRAS, o que constitui uma barreira para a comunicação e dificulta algumas relações interpessoais. Os acontecimentos observados, possibilitaram-nos perceber que as meninas buscam novas experiências e produzem interações importantes com os surdos.

Durante a pesquisa, observamos que, entre os alunos ouvintes do sexo masculino, apenas um fez uso da LIBRAS, em uma comunicação bastante breve com outro aluno surdo, enquanto as alunas ouvintes do sexo feminino buscavam aprender a LIBRAS e faziam uso dela dentro da escola. Entendemos que esse interesse possibilitou uma comunicação com os alunos surdos que frequentavam a escola, incluindo-os no espaço escolar de forma mais efetiva.

Nesse sentido, destacamos uma situação observada e descrita no diário de campo: "um aluno surdo se direcionou a um grupo de meninos ouvintes, próximo à secretaria da escola, nesse grupo apenas um menino ouvinte conversava, em LIBRAS, com o aluno surdo" (Diário de campo do dia 16 de abril de 2019). Esse momento foi o único que presenciamos, durante o período de observações, em que um menino ouvinte que frequenta a fase compreendida entre os Anos Finais do Ensino Fundamental e o Ensino Médio, comunicou-se em LIBRAS. Por mais que tenha sido o único momento, caracteriza o início de uma inserção das pessoas surdas em alguns grupos no ambiente escolar. No entanto, entendemos que os alunos ouvintes do sexo masculino poderiam incluir o aluno surdo nos intervalos e conversarem em LIBRAS, fazendo com que esse aluno surdo fosse incluído em todos os espaços da escola. O que observamos é que eles (ouvintes) não buscam se aproximar dos alunos surdos para dialogar.

O número de alunas ouvintes do sexo feminino que faziam o uso da LIBRAS era maior quando comparado com os meninos ouvintes. Elas demonstraram não se importar em fazer uso dessa língua ou querer aprender mais. Elas interagiam facilmente com os surdos, mostrando-nos que não havia barreiras que as impedissem de ter esse contato com os surdos e a sua língua. Percebemos, também, que quando elas tinham dúvidas sobre algum sinal para determinada palavra, buscavam ajuda ou soletravam para poderem se comunicar. Desse modo, entendemos que, no contexto pesquisado, as meninas buscavam ter uma interação social mais qualificada com os alunos surdos, por meio da LIBRAS. 
Em relação aos alunos dos Anos Iniciais do Ensino Fundamental, destacamos que demonstraram facilidade na comunicação, na interação com o outro, sem diferenciações de gênero. Nessa etapa da escolarização, sentimos que eles demonstraram mais espontaneidade nas formas de pensar ou agir - diferentemente dos alunos dos Anos Finais do Ensino Fundamental e do Ensino Médio -, proporcionando uma interação significativa com todos os alunos, independentemente de sua condição auditiva e do gênero a que manifestam pertencimento.

Sobre esse segundo ponto de discussão, importa marcar que a escola constitui um ambiente de trocas e de produção de saberes, tendo como elementos importantes: a subjetividade dos indivíduos que ali estão, os afetos que constroem, as relações sociais e as interações que estabelecem entre si. Posto isso, entendemos que a escola caracteriza um espaço de constituição e de problematização para as relações de gênero, ensinando modos de ser. De modo geral, o conceito de gênero, tão polemizado nos debates educacionais contemporâneos, traz uma distinção entre homem e mulher, menino e menina. Para Colling e Tedeschi (2019, p. 330), o conceito de gênero "surgiu com força na segunda metade dos anos 1980. [...] Gênero buscaria então dar conta de relações socialmente constituídas dos, [...] gêneros feminino e masculino, suas variações e hierarquização social”. Louro (2008, p. 18) segue na mesma direção ao sinalizar que "fazer de alguém um homem requer, de igual modo, investimentos continuados. Nada há de puramente 'natural' e 'dado' em tudo isso: ser homem e ser mulher constituem-se em processos que acontecem no âmbito da cultura".

O pertencimento a um determinado gênero dita um padrão de normas e condutas sociais que são seguidas por um grupo e que está presente em todos os âmbitos sociais, abrangendo a família e perpassando a escola e os demais espaços de vida coletiva. Vale ressaltar que "a construção do gênero e da sexualidade dá-se ao longo de toda a vida, continuamente, infindavelmente". (LOURO, 2008, p.18). No entanto, a tendência da sociedade é resumir o gênero ao sexo masculino ou feminino (meninos ou meninas), compreendidos como sujeitos diferentes. As escolas, imersas nesse jogo de concepções, trazem culturalmente esses conceitos e os imprimem nas práticas educacionais. Para Louro (1997, p. 60),

[...] essas concepções foram e são aprendidas e interiorizadas; tornam-se quase "naturais" (ainda que sejam "fatos culturais"). A escola é parte importante desse processo. Tal "naturalidade" fortemente construída nos impeça denotar que, no interior das atuais escolas, 
onde convivem meninos e meninas, rapazes e moças, eles e elas se movimentem, circulem e se agrupem de formas distintas.

Levando em consideração esses aspectos, parece-nos importante um olhar mais atento aos alunos, principalmente nesse contexto. Notamos que há pouco uso da LIBRAS pela maioria dos escolares que manifestam pertencimento ao gênero masculino, havendo, de certa forma, uma exclusão dos alunos surdos, no grupo de alunos ouvintes. No entanto, destacamos que os alunos têm uma boa convivência dentro do espaço escolar, por meio de relações de respeito entre ouvintes e surdos. Desse modo, salientamos a importância do uso da LIBRAS dentro da escola, para além das relações de gênero, de modo a possibilitar relações entre diferentes grupos identitários.

Um terceiro ponto a destacar, a partir da materialidade empírica, refere às diferenças nas relações interpessoais existentes entre alunos dos Anos Iniciais do Ensino Fundamental em relação às turmas dos Anos Finais do Ensino Fundamental e do Ensino Médio. Os alunos dos Anos Finais e do Ensino Médio demonstraram conhecimento sobre a LIBRAS, contudo essa condição não se revela nas ações cotidianas e informais na escola. Percebemos que os grupos vão se constituindo e nesse meio há interação e uso da LIBRAS entre surdos e ouvintes, porém não ocorre uma variação de indivíduos, que tendem a se manter sempre no mesmo grupo.

Foi possível observar que, em alguns momentos, ocorreu exclusão de alunos surdos. Uma situação observada se constituiu na hora do lanche, "momento em que uma aluna surda se direciona a uma mesa que tinha alunos ouvintes, porém a ignoram, ela sai dessa mesa e se senta sozinha, não havendo contato, interação com mais ninguém. Isso nos chamou a atenção, pois não teve um aluno ouvinte, que chegasse e fizesse companhia ou tentativa de incluí-la no espaço com os demais alunos ouvintes" (Diário de campo do dia 08 de abril de 2019). Esse comportamento difere do observado com estudantes dos Anos Iniciais, que se apresentavam mais atentos aos surdos, aproximando-se deles e, inclusive, sinalizando com clara intenção de se comunicar.

Observamos que os alunos ouvintes dos Anos Iniciais não só se aproximavam dos alunos surdos como demonstravam entusiasmo em usar a LIBRAS. Faziam questão de mostrar que sabiam fazer uso da língua, não demonstravam vergonha ou medo de se exporem. Sinalizavam com seus colegas e usavam esse momento também como brincadeira. Uma situação registrada no diário de campo elucida as situações acima discutidas: "uma aluna ouvinte 
estava de mãos dadas com uma aluna surda, no refeitório. As duas conversavam em sinais e brincavam. Percebemos que quando a aluna ouvinte não sabia o sinal de alguma palavra, a soletrava usando o alfabeto manual para que a aluna surda entendesse". (Diário de campo do dia 08 de abril de 2019). Esta situação também foi observada em outro momento, envolvendo outras duas alunas, uma ouvinte e outra surda, que "conversavam usando a LIBRAS com apoio do alfabeto manual, da mesma forma exposta anteriormente". (Diário de campo do dia 11 de abril de 2019).

As crianças surdas, precisam ter contato o mais cedo possível com a LIBRAS, assim como uma criança ouvinte precisa estar imersa em um ambiente onde ocorra a comunicação oral, para que ela desenvolva a fala. A criança surda, estando em contato com outras pessoas surdas ou em ambiente escolar onde ocorra o ensino da LIBRAS, aprenderá essa língua e desenvolverá, mais cedo, a capacidade de se comunicar. Entendemos que a oferta da LIBRAS na escola favorece o processo da inclusão dos surdos e contribui para a interculturalidade ${ }^{3}$, buscando um outro meio de as pessoas conhecerem e interagirem com outra língua e outra cultura.

Segundo Padilha (2009), quando alunos surdos e ouvintes estão inseridos numa mesma escola, eles trocam experiências e vivências, organizam-se a partir de uma condição de equiparação no que refere às possibilidades de comunicação e de aprendizagem. Passa a ser conferido a eles o direito à educação de qualidade, ao conhecimento, respeitando cada cultura, adequando-se às diferenças linguísticas e os procedimentos metodológicos. Por fim, para a autora (2009, p. 119), "a escola seriamente comprometida com o aprendizado dos alunos surdos vê e assume o domínio da língua brasileira de sinais para todos que nela estão. Todos ganham em conhecimento; todos ganham em partilha de vida: ouvintes e surdos”.

\section{Considerações finais}

No decorrer dessa pesquisa, discutimos alguns aspectos que nos ajudam a pensar no modo como acontece (como se dá) o uso e a difusão da LIBRAS na escola pesquisada. Entendemos a escola como um ambiente formador, que oferece ferramentas que auxiliarão a comunidade escolar a fazer a inclusão dos alunos surdos.

A partir da pesquisa compreendemos a importância das políticas educacionais de inclusão e de formação de professores, para que se constituam as condições que possibilitem a materialização da inclusão educacional de surdos. No Estado de Santa Catarina, as políticas de inclusão preveem a presença de, pelo menos, quatro profissionais
3 Usamos interculturalidade como um conceito que pode dizer da interação entre culturas sem sobreposição de uma sobre a outra. 
diferentes para o atendimento das especificidades dos escolares surdos: o tradutor/intérprete de LIBRAS/Língua Portuguesa, o professor bilíngue, o instrutor de LIBRAS e o professor de Atendimento Educacional Especializado. A sua presença, na escola pesquisada, parece caracterizar uma forte ênfase da LIBRAS na comunicação entre as crianças surdas e ouvintes nos Anos Iniciais do Ensino Fundamental, embora essa ênfase seja esmaecida nos anos seguintes.

Desde essa concepção de educação bilíngue, via políticas educacionais, parece-nos que a constituição de uma perspectiva bilíngue para a educação se produz a partir de um modelo sociocultural de surdez, que visa atender as especificidades dos surdos, entendendo a sua diferença linguística. Dessa forma, podemos dizer que a escola bilíngue é aquela que trabalha com duas línguas na organização e na operacionalização das suas atividades, mas que procura criar espaços para o ensino da língua materna dos surdos brasileiros. Assinalamos, mais uma vez, que caracteriza um direito do surdo adquiri-la no mesmo tempo em que a pessoa ouvinte adquire sua língua materna, a Língua Portuguesa. Nessa escola e junto aos escolares surdos, é necessário que atuem professores com conhecimento sobre a LIBRAS que consigam pensar, didaticamente, maneiras de adaptação de conteúdos e atividades que atendam às necessidades específicas dos surdos.

A medida que avançamos no processo de escolarização, percebemos que, na escola pesquisada, apenas um determinado grupo de alunos ouvintes fazia uso da LIBRAS. Consideramos que esse número de alunos ouvintes que a utilizavam é inferior à expectativa que tínhamos, por se tratar de uma escola referência na inclusão de alunos surdos e no ensino da LIBRAS. Esperávamos que a comunicação entre os alunos ouvintes e surdos fosse mais frequente. Dessa forma, entendemos que a escola poderia reavaliar a forma de oferta da LIBRAS e a organização de uma ênfase bilíngue para o contexto escolar, de modo que a LIBRAS passe a se configurar como segunda língua para os alunos ouvintes e seja garantida como primeira língua para os alunos surdos.

Não podemos deixar de destacar a ausência de registros históricos sobre a implantação da inclusão de surdos nesta escola que é considerada como escola pólo, constituindo-se como referência na educação de surdos, no município. Os registros são fontes de pesquisa e conhecimento sobre os mais variados aspectos da história. Eles documentam modos de vida, de sociedade, de visão de mundo, de formas encontradas para a resolução de problemas em diferentes épocas. Consideramos importante a existência de algum registro, de documentos que acompanhassem essa 
trajetória, no caso, a trajetória da educação de surdos na escola e dos processos de inclusão que antecedem, inclusive, a legislação brasileira. Assim como não há registros sobre o início do trabalho com surdos na escola, também não há registros sobre os planejamentos, as discussões e a definição sobre o ensino de LIBRAS, mesmo não fazendo parte, oficialmente, do currículo formal da escola.

Por fim, ficamos inquietos com as questões relacionadas ao gênero, que mobilizavam o uso da LIBRAS a partir dos Anos Finais do Ensino Fundamental, estendendo-se para o Ensino Médio. Dados os limites dessa pesquisa, não nos foi possível estudar mais a fundo e compreender os motivos que restringem o uso da LIBRAS, na comunicação entre surdos e ouvintes que frequentam os Anos Finais e o Ensino Médio, ao gênero feminino. Para uma análise mais aprofundada dessa questão precisaríamos de outros instrumentos de produção de dados. Diante disso, fica uma possibilidade de seguir em outras pesquisas para compreender o que provoca um apagamento no uso da LIBRAS entre os escolares que manifestam pertencimento ao gênero masculino, na escola pesquisada.

Para que inclusão de surdos ocorra de forma positiva, parece-nos necessário, ainda, que as escolas insiram o ensino da LIBRAS nos currículos, como forma de os alunos aprenderem a LIBRAS, desde os primeiros anos da escolarização até os anos finais. A LIBRAS necessita de prática e estudos contínuos para que alcance um nível satisfatório para a comunicação. Esse acesso poderia se estender para toda a comunidade escolar, especialmente a todos os funcionários da escola. Dessa forma, o ensino da LIBRAS contribuiria para a inclusão do aluno surdo no espaço escolar e na sua autonomia de um modo geral.

Ao finalizar a pesquisa ficaram algumas indagações, que nos levam a pensar e questionar o modelo de ensino atual: será que as escolas de ensino comum reúnem as condições materiais, humanas (quadros docentes, tradutores/ intérpretes, instrutores de LIBRAS, etc.), pedagógicas e políticas para ofertar um ensino bilíngue? Parece-nos que ainda temos muito a avançar em termos de políticas educacionais, de materialização dos processos de escolarização e nas relações sociais para contemplar e compreender a singularidade provocada pela surdez. Entretanto, salientamos a importância de experiências como as da escola pesquisada, no que refere ao ensino da LIBRAS, direcionando-o para todos os escolares que a frequentam. A partir do ensino de LIBRAS, comum a todos, são produzidas as condições para a inclusão dos alunos surdos, possibilitando que a sua comunicação não fique restrita aos professores bilíngues, tradutores/intérpretes, instrutores de LIBRAS ou aos colegas surdos no espaço da escola, mas ampliando as 
trocas comunicativas com todos os ouvintes e viabilizando o diálogo com seus colegas.

\section{Referências}

BRASIL. Ministério do Planejamento, Orçamento e Gestão. Censo Demográfico 2010: Características gerais da população, religião e pessoas com deficiência. Rio de Janeiro: Instituto Brasileiro de Geografia e Estatística, 2012.

BRASIL. Lei no 10.436, de 24 de abril de 2002 - Dispõe sobre a Língua Brasileira de Sinais - Libras e dá outras providências. Brasília, DF: Presidência da República. Disponível em: http://www.planalto.gov.br/ccivil_03/ LEIS/2002/L10436.htm. Acesso em: 02 abr. 2019.

BRASIL. Decreto no $\mathbf{5 . 6 2 6}$, de 22 de dezembro de 2005 - Regulamenta a Lei $\mathrm{n}^{0}$ 10.436, de 24 de abril de 2002, que dispõe sobre a Língua Brasileira de Sinais - Libras, e o art. 18 da Lei $\mathrm{n}^{0} 10.098$, de 19 de dezembro de 2000. Disponível em: http://www.planalto.gov.br/ccivil_03/_ ato2004-2006/2005/decreto/d5626.htm. Acesso em: 26 maio 2019.

BRASIL. Ministério da Educação. Política Nacional de Educação Especial na perspectiva da Educação Inclusiva. Brasília: SEESP, 2008.

COLLING, Ana Maria; TEDESCHI, Losandro Antonio. Dicionário Crítico de Gênero. Dourados: Editora UFGD, 2019.

COMISSÃO de Educação aprova proposta do ensino de Libras obrigatório nas escolas públicas brasileiras. Revista Exame. Maio 2019. Disponível em:https://exame.abril. com.br/negocios/dino/comissao-de-educacao-aprova-proposta-do-ensino-de-libras-obrigatorio-nas-escolas-publicas-brasileiras/. Acesso em: 25 maio 2019.

FERREIRA, Maria Cecília Carareto; ZAMPIERI, Marinês Amália. Atuação do professor ouvinte na relação com o aluno surdo: relato de experiência nas séries iniciais do ensino fundamental. In. LODI, Ana Claudia Balieiro; LACERDA, Cristina Broglia Feitosa de. Uma escola, duas línguas: letramento em língua portuguesa e língua de sinais nas etapas iniciais de escolarização. Porto Alegre: Editora Mediação, 2009.

FRÖHLICH, Raquel. Práticas de apoio à inclusão escolar e a constituição de normalidades diferenciais. 2018. 221f. Tese (Doutorado em educação), Programa 
de Pós-Graduação em Educação, Universidade do Vale do Rio dos Sinos, São Leopoldo, 2018.

KELMAN, Celeste Azulay; LAGE, Aline Lima da Silveira; ALMEIDA, Simone D’Avila. Bilinguismo e Educação: práticas pedagógicas e formação de professores. In: Revista Espaço. Rio de Janeiro, n. 44, jul./dez., 2015.

LACERDA, Cristina Brogila Feitosa de; ALBRES, Neiva de Aquino; DRAGO, Silvana Lucena dos Santos. Política para uma educação bilíngue e inclusiva a alunos surdos no município de São Paulo. In: Educação e Pesquisa. São Paulo, v.39, n.1, 2013.

LOURO, Guacira Lopes. Gênero e sexualidade: pedagogias contemporâneas. In: Pro-Posições, v. 19, n. 2, maio/ago., 2008.

LOURO, Guacira Lopes. Gênero, sexualidade e educação. Uma perspectiva pós-estruturalista. Petrópolis, RJ. Editora Vozes, 1997.

MARQUES, Hivi de Castro Ruiz; BARROCO, Sonia Mari Shima; SILVA, Tânia dos Santos Alvarez. O Ensino da Língua Brasileira de Sinais na Educação Infantil para Crianças Ouvintes e Surdas: Considerações com Base na Psicologia Histórico-Cultural. Revista Brasileira de Educação Especial, v.19, 2013.

MATTOS, Carmem Lúcia Guimarães de; CASTRO, Paula Almeida de. Etnografia e educação: conceitos e usos. Campina Grande: EDUEPB, 2011.

PADILHA, Anna Maria Lunardi. Uma escola, duas línguas letramento em língua portuguesa e língua de sinais nas etapas iniciais de escolarização: Desafio para a formação de professores: alunos surdos e ouvintes na mesma sala de aula?. 2. ed. Porto Alegre: Editora Mediação, 2009.

PPP - Projeto Político Pedagógico. Escola de Educação Básica Marechal Bormann, 2018.

SANTA CATARINA. Política de Educação Especial. Florianópolis: Secretaria de Estado de Educação, 2018.

SANTANA, Ana Paula. Surdez e linguagem: aspectos e implicações neurolinguísticas. São Paulo: Editora Plexus, 2007. 